\title{
The use of golden proportion in dentistry: a integrative review
}

Luisa Piazzon Tridapalli ${ }^{\mathrm{a}}$, Marina Steinbach ${ }^{\mathrm{a}}$

\begin{abstract}
OBJECTIVE: The purpose of this integrative review was assembling information about the golden ratio, improving a different sight to the theme.

METHODS: Original articles were retrieved on databases Scielo, PubMed, Lilacs and Web of Science selecting proper articles published between the years of 2006- 2017.

RESULTS: 55 articles were included, in which $42 \%$ of the findings corresponded to aesthetic perception and $40 \%$ to golden ratio and ethnical groups.

CONCLUSION: The findings suggest that there's no relationship between golden ratio and natural teeths and this ratio isn't a decisive factor to ensuring the smile attractiveness, however, if this proportion were individually applied for each patient, can become a useful guide.
\end{abstract}

Keywords: golden ratio; dentistry; aesthetics; smile; parameters.

\section{O uso da proporção áurea na odontologia: uma revisão integrativa}

\section{RESUMO}

OBJETIVOS: O objetivo dessa revisão integrativa foi condensar informações acerca da proporção áurea possibilitando que o cirurgião dentista tenha uma visão aprimorada sobre o assunto.

METODOLOGIA: Foi realizada uma busca nas bases de dados Scielo, PubMed, Lilacs e Web of Science entre os anos de 2006 a 2017 selecionando artigos condizentes com o escopo da pesquisa.

RESULTADOS: Foram utilizados 55 artigos, em que $42 \%$ dos achados correspondiam a percepção estética e $40 \%$ relacionados a grupos étnicos e proporção áurea.

CONCLUSÃO: Não foram encontradas relações entre proporção áurea e a dentição natural das populações e nem como um fator determinante para avaliar a atratividade de um sorriso, porém, se utilizada de maneira personalizada para cada paciente, ela pode vir a ser um guia de grande utilidade.

Palavras-chave: proporção áurea; odontologia; estética; sorriso; parâmetros.
Department of dentistry, Fundação Universidade Regional de Blumenau (FURB), Blumenau, Brazil

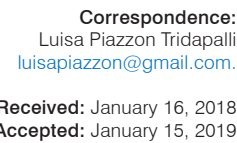

Accepted: January 15,2019

Conflict of Interests: The authors state that there Con financial and personal conflicts of interest that could have inappropriately influenced their work.

Copyright: (C) 2018 Tridapalli \& Steinbach; licensee EDIPUCRS.

This work is licensed under a Creative Commons Attribution 4.0 International License. 


\section{INTRODUCTION}

In our current society, aesthetics is overvalued and primarily related to how well individuals are accepted in social groups. People are routinely exposed to countless amounts of information and methods to achieve the beauty standard found in celebrities or digital influencers, who, in turn, disclose through social media the many procedures they have followed to reach the aesthetic goal. As a result, several people are encouraged to seek the same kind of treatment or procedures.

The ease of access to information which was previously restricted to plastic surgery and dentistry professionals, the XXI century patient arrives at the clinic knowing details of the procedures. Therefore, there is a demand for professionals with deep technical/scientific knowledge to explain the limitations and particularities of each technique. Dentistry is a key tool in the search for the ideal smile; hence, several procedures are now widespread to that end, such as dental laminates and bichectomy.

According to Schubert (2009) [1], the pursuit of beauty is as ancient as human kind. Many cultures over time have shown their preferences and tastes through their beauty standards. In the tribal period, procreation and breastfeeding were the aesthetic requirements that defined a beautiful woman. Men needed to be strong and intelligent to be portrayed as handsome, as those were essential requirements to defend the offspring. During the medieval period, beauty was related to the devotion to God. Men should take care of his family and women ought to be a good mother, raising their children according to the Christian principles. These traits defined survival and became values influencing the cultural context [1].

According to Tatarkiewicz (1991) [2], to the Greeks the human body was based in mathematical proportions, which could be reproduced in artistic endeavors. To them, beauty was all about the details, mainly in the face. Always based on mathematical standards or references, the Greek built some of the most gorgeous and magnificent temples, such as Partenon and the most beautiful sculptures, such as Venus de Milo or Apollo of the Belvedere. These masterpieces were built following the Golden Ration principle [2].

According to Huntley (1985) [3], it is most certain the usage of this ration in the Greek works. Phidias, a famous Greek sculptor, was used as reference to indicate the golden ratio with the first letter of his name, phi $(\varphi)$. The gold number (or phi number) is 1.61803. Later in history, this value was described in Math by Fibonacci, in which the value of a term is the sum of the previous two terms (ex.: $1+1=2 ; 1+2=3 ; 2+3=5$ and so forth) and the ration between these two factors is 0.618 , which explains the ration of 1 to 1.618 [4]. Some of the oldest references about this ratio are linked to the Greek philosopher Pythagoras. To him, nature presented relations and combinations that could only be explained with the science of numbers [3]. In nature, this proportion can be observed in some flowers, such as
Azalea, petunia and sunflowers, as well as in some shells and clams [4].

The golden ratio was introduced in several fields of study and in Dentistry it was no different. The first apparition in aesthetic dentistry was in the 70's, through Lombardi (1973) [5]. In 1978, Levin [6] wrote about some of the many forms that the golden ration appears in nature and how it applies to aesthetic dentistry. In the field of facial analysis, Ricketts (1982) [7] had great prominence by measuring some attractiveness parameters against the golden ration. Preston (1993) [8] also deserves recognition for his work on golden ratio in aesthetic dentistry. He assessed several aspects of the smile and concluded that the golden ration was present only between the central and lateral incisors.

Although there are some studies about the usage of golden ratio in dentistry, it is noticeable the absence of relevant information on how to put this concept to practice, which causes a sense of doubt about its purpose. Therefore, this paper aims to consolidate information about the golden ratio, summarizing several studies and researches, offering deeper insight on the subject to dental surgeons, supporting them on the choice of techniques for aesthetic procedures.

\section{METHODS}

Considering the various research methods that aim to obtain summarized information about a given topic, the method of choice for this paper is integrative review, as it allows an in-depth methodic approach, enabling the integration of experimental and non-experimental studies [9]. According to Baldini Soares et al. (2014) [10], integrative review seems to be useful in the creation and formulation of research problems in new theories and define this approach as a complex review, which requires systematic and methodological rules in order to obtain the appropriate level of accuracy for scientific researches. It also compiles data from theoretical and empirical literature, aggregating several resolutions, such as theory and evidence review, analysis of methodological problems and definition of concepts. The integrative review establishes the current perception of a given theme, supporting the quality of delivered services to the patients, rating protocols, procedures and critical thinking required for the daily routine [11].

The integrative review is part of the field called Evidence Based Research (EBR), which aims to reinforce the importance of research for clinical practice. It assesses the available evidence from studies and proposes solutions to the decisions; hence, it provides aid for health procedures based on scientific knowledge [12]. The goal of literature integrative review is to enable the meaningful comprehension of a given theme, based on preview studies. To that end, precise standards of methodology are followed, as well as appropriate interpretation of results, enabling the reader to determine the quality of the studies used in the review [12]. The integrative 
review allows the reader to access all the information from a given study and not only the main results, enabling a clearer and more complete reading of the theme [10].

The integrative review is organized in phases recommended by Ganong (1987) [13]. The first phase is completed by formulating one objective and one question for the theme of study; the second phase consists of specifications to include studies; the third phase comprehends selecting the studies; the fourth phase develops a questionnaire to gather data, which for this paper was done by a categorization to separate similar information regarding the theme; the fifth phase assesses the studies with the questionnaire, analyzing the methodology and conclusions of each study; the sixth phase evaluates the information found and the seventh and eighth phases are for discussion and interpretation of the findings.

This paper was started with the question: How can the golden ration be used in dentistry? To answer these questions, a bibliographic review was done in the following data bases: Lilacs, SciElo, Pubmed/MedLin, Web of Science, in the months from April 2017 to October 2017, searching the themes "golden proportion and dentistry" and "golden proportion and teeth" and "golden proportion and aesthetic". As part of the second phase of the integrative review, articles in any languages were considered, as long as fully available online, as well as published between January 2006 and September 2017 (due to the high amount of articles in the period). Editorials, letter to readers, theses, partially available online studies and duplicate articles were dismissed. The identified articles were pre-selected based on the title and summary, and those which met the selection criteria were read and recorded. After the selection, the articles were categorized as such: articles related to aesthetic perception, golden ration in different ethnic groups, golden ration and dentistry, clinic cases of golden ratio, among others. Afterwards the studies were deemed valid, the agreements and disagreements between different authors were noted so that readers would have a quick access to relevant results of the studies, based on different approaches to the golden ratio.

\section{RESULTS AND DISCUSSION}

The research was carried out in the data bases, identifying 93 articles under "Golden proportion and aesthetic", 83 under "Golden proportion and dentistry" and 87 under "Golden proportion and teeth", totaling 263 articles. Based on the summaries, titles and publication year (from January 2006 to September 2017), 188 articles were pre-selected, out of which 117 were duplicates. Hence, the final amount was 71 papers. To analyze the papers, all of them were read and 16 articles were deemed out of the desired scope, leaving a total of 55 valid articles. The findings were grouped by theme similarity, being: dentistry/malocclusion, aesthetic perception, clinic cases, ethnic groups and agenesis of upper lateral incisors. Table 1: found articles per title, author and publication year.
Table 1. Represents the evaluated articles

Year Title/Autor

2017 Effects of malocclusions on facial attractiveness and their correlations with the divine proportion - AKAN, Seden; TORGUT, Ayse Gul; OKTAY Hüsamettin

2017 Perception of Acceptable Range of Smiles by Specialists, General Dentists and Lay Persons and Evaluation of Different Aesthetic Paradigms - SAHA, Mainak Kanti et al.

2017 Quantification of facial and smile esthetics. KOIDOU, Vasiliki P.; CHATZOPOULOS, Georgios S.; ROSENSTIEL, Stephen F.

2017 Premium protocol for planning a periodontal-restorative approach: Conservative, predictable, and reproducible DA CUNHA, Leonardo Fernandes et al.

2017 Evaluation of widths of maxillary anterior teeth and their relation to the golden proportion in the southwestern part of Saudi Arabia KANAPARTHY, Rosaiah et al.

2017 Analysis of the width ratio and wear rate of maxillary anterior teeth in the Korean population. $\mathrm{OH}$, Yeon-Ah et al.

2016 Golden Proportion Analysis of Dental-Skeletal Patterns of Class II and III Patients Pre and Post Orthodontic-orthognathic Treatment. BRAGATTO, Fernanda P. et al.

2016 Comparative photographic evaluation of various geometric and mathematical proportions of maxillary anterior teeth: A clinical study. AGRAWAL, Vineet $\mathrm{S}$. et al.

2016 Estudo das proporções dentárias utilizando os métodos de Bolton e Levin. Dos Santos, Pedro César Fernandes et al

2016 Tooth Morphology and Aesthetics While Smiling in Accordance to Golden Proportion. MUHAMMAD, Sher; SHAHID, Rehman; SIDDIQUI, Muhammad Ismail.

2016 Does the maxillary anterior ratio in Korean adults follow the Golden Proportion?. JIN, Ming-Xu et al.

2016 Photographic and manual evaluation of golden percentage and recurrent aesthetic dental proportion in aesthetic smiles. NIRANJAN Nandini T. et al.

2016 Mestizo Anterior Teeth's RAMIREZ, Luis Miguel; OSPINA, Juan David; BALLESTEROS, Luis Ernesto.

2015 Morphological features of maxillary anterior teeth in a sample of Chinese population. - ZHAO, Qingbo; LI, Nan; CAO, Jun

2015 Vertical and horizontal proportions of the face and their correlation to phi among Indians in Moradabad population: A survey. ANAND, Shruti et al.

2015 Multiracial facial golden ratio and evaluation of facial appearance ALAM, Mohammad Khursheed et al.

2015 An analysis of maxillary anterior teeth dimensions for the existence of golden proportion: clinical study. SANDEEP, Nalla et al.

2015 The unique contribution of elements of smile aesthetics to psychosocial well-being. LUKEZ, A. et al

2015 Selecting maxillary anterior tooth width by measuring certain facial dimensions in the Kurdish population. NEDA, AL-Kaisy; GARIB, Balkees Taha.

2015 Avaliação da proporção áurea no sorriso de pacientes submetidos ao tratamento ortodôntico. MARCONATO, Juliana Cristina et al.

2015 Algunos factores relacionados con la estética dental: una nueva aproximación. BECERRA SANTOS, Gerardo et al.

2014 Evaluation of the putative ratio rules for facial beauty indexing - CHEN, Fangmei; ZHANG, David.

2014 Anthropometric analysis of anterior maxillary teeth with digital photography-a study in a Portuguese sample CALÇADA, Diogo; CORREIA, André; ARAÚJO, Filipe.

2014 Maxillary anterior teeth dimensions and proportions in a central mainland chinese population. SAH, S. K. et al.

2014 Cleidocranial dysplasia case report: remodeling of teeth as aesthetic restorative treatment. Case reports in dentistry DA CUNHA, Leonardo Fernandes et al.

2013 Esthetic paradigms in the interdisciplinary management of maxillary anterior dentition - a review. RAJ, Vishnu

2013 The role of the golden proportion in the evaluation of facial esthetics. ROSSETTI, Alberto et al. 
Table 1 (conclusion)

\section{Year Title/Autor}

2013 Assessment of Facial Golden Proportions among North Maharashtrian Population. SUNILKUMAR, L. N. et al.

2013 Width ratios in the anterior maxillary region in a Hungarian population: addition to the golden proportion debate. FORSTER, András et al.

2013 A study to evaluate the prevalence of golden proportion and RED proportion in aesthetically pleasing smiles MESHRAMKAR, $R$. et al.

2013 The golden ratio in facial symmetry. PROKOPAKIS, Emmanuel P. et al.

2013 Evaluation of maxillary anterior teeth and their relation to the golden proportion in Malaysian population. AL-MARZOK, Maan Ibrahim; MAJEED, Kais Raad Abdul; IBRAHIM, Ibrahim Khalil.

2012 The assessment of dentofacial esthetics in restorative dentistry: a review of the literature. RESE, Cornelia; STAEHLE, Hans Joerg; WOLFF, Diana.

2012 Analysis of the golden proportion and width/height ratios of maxillary anterior dentition in patients with lateral incisor agenesis PINI, Núbia Pavesi et al.

2012 Golden proportion assessment between maxillary and mandibular teeth on Indian population CHANDER, Naveen Gopi; KUMAR, Vaikunth Vijay; RANGARAJAN, Vedantham.

2012 Incidência da Proporção Áurea Regressiva após Tratamento Ortodôntico MAYUMI, Paula Siqueira et al.

2012 Photometric study of divine proportion and its correlation with facial attractiveness PERON, Ana Paula Lazzari Marques et al.

2011 Evaluation of different esthetic smile criteria AL-JOHANY, Sulieman S. et al.

2011 Dentofacial deformities treated according to a dentoskeletal analysis based on the divine proportion: are the resulting faces de facto divinely" proportioned? SCOLOZZI, Paolo; MOMJIAN, Armen COURVOISIER, Delphine.

2011 Maxillary anterior tooth dimensions and proportions in an Irish young adult population. CONDON, Mark et al.

2010 Inner canthal distance and golden proportion as predictors of maxillary central incisor width in south Indian population. GEORGE, Shibu et al.

2010 Estudo da Proporção Áurea em pacientes jovens Classe II, divisão 1 tratados ortodonticamente DE ANDRADE BRUM, Carlota Verônica et al.

2010 Proportions of maxillary anterior teeth relative to each other and to golden standard in tabriz dental faculty students. PARNIA, Fereydoun et al.

2009 Assessment of the golden ratio in pleasing smiles. NIKGOO, Arash et al.

2009 . Assessment of facial golden proportions among young Japanese women. MIZUMOTO, Yasushi; DEGUCHI, Toshio; FONG, Kelvin WC.

2008 Appropriate proportions as guidelines in selection of anterior denture teeth. PETRIČEVIĆ, Nikola et al.

2008 Putative golden proportions as predictors of facial esthetics in adolescents KIEKENS, Rosemie MA et al.

2008 Evaluation of natural smile: Golden proportion, RED or Golden percentage. MURTHY, BV Sreenivasan; RAMANI, Niketa.

2007 The influence of varying maxillary lateral incisor dimensions on perceived smile aesthetics. BUKHARY, S. M. N. et al.

2007 A study of dentists' preferred maxillary anterior tooth width proportions: comparing the recurring esthetic dental proportion to other mathematical and naturally occurring proportions WARD, Daniel $\mathrm{H}$.

2006 Comparative study of smile analysis by subjective and computerized methods. BASTING, R. T.; TRINDADE, R. S.; FLORIO, F. M.

2006 Geometric and mathematical proportions and their relations to maxillary anterior teeth. ALI FAYYAD, M.; JAMANI, K. D.; AGRABAWI, J..

2006 Peer assessment of dental attractiveness. ONG, Egle; BROWN, Rebecca A.; RICHMOND, Stephen.

2006 Subjective and objective perception of upper incisors. WOLFART, S et al.

2006 Prevalência da proporção áurea em indivíduos adultos-jovens. SOARES, Giulliana Panfiglio et al.
In the selected period, the year 2015 presented the highest number of publications (8-14.54\%) followed by 2016 (7-12.72\%) and 2013 (7-12.72\%). The Figure 1 represents articles per year.

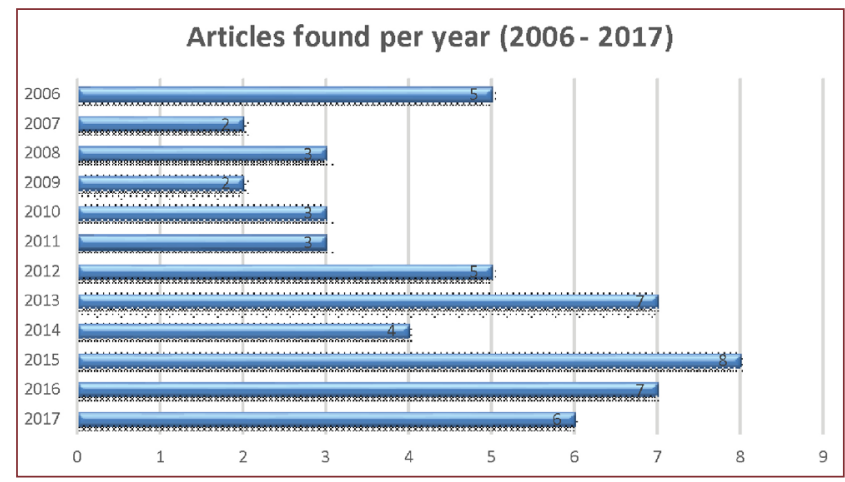

Figure 1. Articles per year.

The publications in general are from parts of the world, such as Asia, Europe, Latin America and North America. The grouping of articles correspond to 2 articles about agenesis of upper lateral incisors, 3 clinic cases, 5 dentistry/ malocclusion, 22 ethnic groups and 23 aesthetic perception (Figure 2). This paper considers aesthetic perception those articles that relate the perception of a group of individuals to attractive smiles.

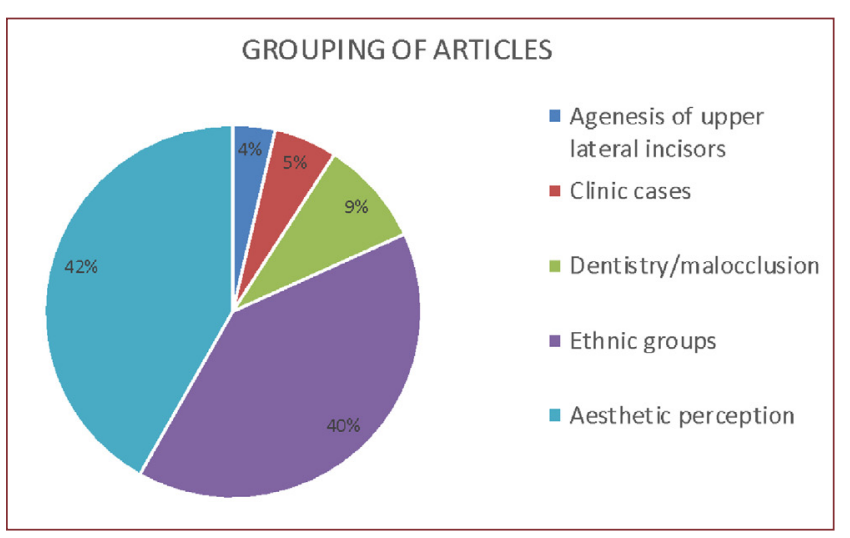

Figure 2. Provision of themes

\section{Ethnic groups}

Analysis of the golden ratio in different ethnicities show that countries such as Saudi Arabia, India, Japan, Turkey and Ireland present in their population some references to the measurements established by the golden ratio [14-20], whilst Korea, Pakistan, Colombia, China, Hungary, Malaysia, Iran and Brazil [21-32] did not show any relation to the golden ratio.

These facts indicate that the standardization of a single concept to establish ideal measurements for attractiveness is not real. This integrative review demonstrates that studies performed in a population have divergent results in India, Korea, China and Malaysia. 
Clinic cases and agenesis of upper lateral incisors

When used in clinic cases, $100 \%$ of the studies concluded that for size and proportion dental discrepancy, aesthetics can be reestablished with support from the golden ratio [33] and the usage of this simple and predictable technique in surgeries and dental facet placement achieves pleasant aesthetic results [34]. Therefore, the golden ratio can be used as a guideline for harmonization and remodeling of smiles [35].

Pini et al. (2012) [36] and Bukhary et al. (2007) [37] concluded that the golden ratio is not necessary in the recreation of smiles with agenesis of lateral incisors and that there are no evidences to support that golden ratio should be considered an ideal standard in replacement of lateral incisors.

\section{Aesthetic perception}

In the book Molly Bawn, written in 1879 by Margaret Hungerford, is the classic sentence "the beauty is in the eyes of the beholder". Despite of its age, the sentence remains true and exemplifies the view of Akan; Torgut and Oktay (2017) [38] about beauty; to them, the beauty is determined by the judgement of the beholder and it changes according to the culture and individuals. This view has been proved true in this paper, in which several ethnicities were evaluated and achieved various results. In the population of India, Niranjan et al. (2016) [15], Sunilkumar et al. (2013) [16] and George et al. (2010) [17] found a relationship between this population and the golden ratio, while Anand et al. (2015) [39], Sandeep et al. (2015) [40] and Chander; Kumar and Rangarajan (2012) [41] did not find relation between the population and the golden ratio. This fact is due to the different criteria used to determine which part of the face had the golden ratio.

The main results found during the data gathering process related to aesthetic perception. Saha et al. (2017) [42] concluded that an individual numeric parameter does not define the beauty of a smile, supporting the findings of Basting; Trindade and Florio (2006) [43], which state it is not possible to establish single criterion to define adequate aesthetics. This proportion is not a defining factor in dental aesthetics [44] because when assessing the smiles of celebrities or common individuals of the general population, both showed divergences in relation to the golden ratio [45], indicating that this is not a valid method to determine the attractiveness of a smile [46]. Corroborating with these studies, Murthy; Bv and Ramani (2008) [47] concluded that only $14 \%$ of individuals of their research showed the golden ratio in the natural anterior teeth. With the exception of the study by Koidu; Chatzopoulos and Rosernstiel (2017) [45], that evaluated several smiles only by measuring photos of celebrities and regular people, the other studies mentioned in this paper used assessment methods based in the particular opinion of each jury. In the research of Nikgoo et al. (2009) [46], for example, the jury was composed by one orthodontist, one prosthetist, one photographer and one painter. As well as the calibration might have been done, the individual opinion and ideology of each background remains unique, possibly interfering in the final results.

In spite of the golden ratio have been expressed as an aesthetical standard for decades, it is not routinely used [48] and is not commonly found in natural smiles [49]. However, it can be useful to meet both patients and dentists expectations for aesthetic rehabilitation, if used considering the particularities of each individual $[14,35,50,51,52]$. Petričević et al. (2008) [53] concluded that Golden ratio should not be used in clinic practice as a guide to achieve the ideal aesthetic, however, Solozzi; Momjjan and Courvoisier (2011) [54] quoted the golden ratio has shown effective in correcting the inferior third part of the face and Ward (2007) [55] that it can be used to plan smiles with high teeth.

\section{Dentistry and malocclusion}

Lukez et al. (2015) [56], assessed the elements of the aesthetic smile and their contribution to the well-being of teenagers. In the end of the research, concluded that the aesthetic concern with the golden ratio standard was responsible for only $2 \%$ of the results, being the severity of malocclusion the most important factor $(18 \%)$. On the other hand, Akan; Torgut and Oktay (2017) [38] demonstrated that malocclusion is not related to the individual's attractiveness as well as the golden ratio is not tied to the beauty of a person. Bragatto et al. (2016) [57], sought to identify whether the cephalometric standards approximate to the golden ratio after orthognathic surgery in Angle's Class II and III patients. The analysis showed out of the 13 standards defined by Ricketts, only one came close to the golden ratio after the surgery, demonstrating that the golden ratio was not present.

Supporting these results, Marconato et al. (2015) [50] concluded that the golden ratio was verified in $67.56 \%$ of patients at the end of dental treatment, showing it can be applied to ensure a harmonic and aesthetic smile. This result goes in line with the findings by Mayumi et al., (2012) [58] in which $62 \%$ of analyzed patients presented a standard that during the treatment became closer to the golden ratio value, being called regressive golden ratio. It also goes in line with the study by De Andrade Brum et al. (2010) [59], in which most parts of facial proportions do not relate to the golden ratio, however, at the end of the dental treatment, the values became closer to the ones established by the golden ratio, confirming the findings in the study by Prokopakis et al. (2013) [60], that dentists can use the golden ratio if they are looking for attractive, symmetric and standardized aesthetic values.

When the golden ratio is assessed and used in accordance to the particularities of each individual, and not in a frantic pursuit to achieve the exact values, the results are encouraging, harmonic, natural and real.

\section{Gender differences}

The prevalence of golden ratio is different between genders, to Kanaparthy et al. (2017) [14], in Saudi Arabia, 
the proportion has been found between the central and lateral incisors of women and between lateral incisors and the canine tooth in men. Some studies found higher prevalence of golden proportion in women [18,23,32]. As opposite, other studies demonstrated the golden ratio was more common in men than women $[19,15,61,62]$. To Condon et al. (2011) [20] there was no significant differences in the values found for both gender.

In adulthood, cephalometric evaluation differs between genders, whilst in puberty it is almost impossible to determine the sex of the individual analyzing the skull. In women, the supraorbital margins are sharper and the paranasal sinuses are smaller than in men. Similarly, the jaw structure is thinner, and the glabella is less developed. The zygomatic bone has the lower edge irregular and rough in men and smooth and regular in women [63]. These differences illustrate that when assessing facial structures, the gender of the patient must be taken into account, not excluding anatomic differences, but adapting to them.

\section{CONCLUSION}

The findings in this integrative review identified the possibility of using the golden ratio as a guide in aesthetic rehabilitation as long as the characteristics of each individual are taken into account, because the reading of articles revealed that, as an isolated factor, the golden ratio is not decisive in dental aesthetic. In this paper did not find significant evidence that the proportion is naturally present in populations, since several factors must be equally analyzed.

In order to the benefits of the golden ration surpass the particularities of the techniques, the dentist surgeon must keep in mind that the proportion should not be deemed as a general rule to be applied deliberately to standardize smiles, but as a harmonization tool to be individually applied to each case. All the concepts that create the harmony between smile and facial aesthetics must be taken into account, analyzing the individual inwards, understanding the patient's desires, needs and expectations.

\section{REFERENCES}

1. Schubert C. A construção do conceito estético Ocidental e sua implicação na formação valorativa e no processo educacional. In: Divisão Temática Interfaces Comunicativas do X Congresso de Ciências; 2009.

2. Tatarkiewicz W. Historia de la estética III: La estética moderna, 1400-1700. Ediciones Akal; 1991.

3. Huntley HE. A Divina proporção um ensaio sobre a beleza na matemática. Universidade de Brasília; 1985.

4. Mendias Lauro M. A razão áurea e os padrões harmônicos na natureza, artes e arquitetura. Exacta 2005;3

5. Lombardi RE. The principles of visual perception and their clinical application to denture esthetics. The Journal of prosthetic dentistry 1973:29:358-82. https://doi.org/10.1016/S0022-3913(73)80013-7

6. Levin El. Dental esthetics and the golden proportion. The Journal of prosthetic dentistry 1978;40(3). https://doi.org/10.1016/0022 3913(78)90028-8

7. Ricketts RM. The biologic significance of the divine proportion and Fibonacci series. American journal of orthodontics 1982:81:351-70. https://doi.org/10.1016/0002-9416(82)90073-2

8. Preston J. D. The golden proportion revisited. Journal of Esthetic and Restorative Dentistry 1993;5:247-51. https://doi.org/10.1111/ j.17088240.1993.tb00788.x
9. Broome, ME. Integrative literature reviews for the development of concepts. Concept development in nursing: foundations, techniques and applications. Philadelphia: WB Saunders Company; 2000. p. 231-50.

10. Baldini Soares $C$ et al. Revisão integrativa: conceitos e métodos utilizados na enfermagem. Revista da Escola de Enfermagem da USP 2014;48(2)

11. De Souza MT, da Silva MD, de Carvalho R. Revisão integrativa: o que é e como fazer. Einstein 2010;8(1 Pt 1):102-6.

12. Dal Sasso Mendes K, Campos Pereira Silveira RCD, Galvão CM. Revisão integrativa: método de pesquisa para a incorporação de evidências na saúde e na enfermagem. Texto \& contexto enfermagem 2008;17(4)

13. Ganong LH. Integrative reviews of nursing research. Research in nursing \& health 1987;10(1):1-11

14. Kanaparthy, $\mathrm{R}$, et al. Evaluation of widths of maxillary anterior teeth and their relation to the golden proportion in the southwestern part of Saudi Arabia. Journal of Research in Medical and Dental Science 2017;4:83-86. https://doi.org/10.5455/jrmds.2016422

15. Niranjan NT, Kanaparthy A, Kanaparthy R, Kiran HY. Photographic and manual evaluation of golden percentage and recurrent aesthetic dental proportion in aesthetic smiles. Journal of Evolution of Medical and Dental Sciences 2016;5:2267-71.

16. Sunilkumar LN et al. Assessment of Facial Golden Proportions among North Maharashtri-an Population. Journal of international oral health: $\mathrm{JIOH}$ 2013;5(3):48

17. George S, Bhat V. Inner canthal distance and golden proportion as predictors of maxillary central incisor width in south Indian population. Indian Journal of Dental Research 2010;21:491. https://doi. org/10.4103/0970-9290.74214

18. Mizumoto Y, Deguchi T, Fong KW. Assessment of facial golden proportions among young Japanese women. American Journal of Orthodontics and Dentofacial Orthopedics 2009;136:168-74. https://doi.org/10.1016/j. ajodo.2007.07.029

19. Neda AK, Garib BT. Selecting maxillary anterior tooth width by measuring certain facial dimensions in the Kurdish population. The Journal of prosthetic dentistry 2015;115:329-34.

20. Condon $\mathrm{M}$ et al. Maxillary anterior tooth dimensions and proportions in an Irish young adult population. Journal of oral rehabilitation 2011;38(7): 501-8. https://doi.org/10.1111/j.1365-2842.2010.02181.x

21. Oh YA et al. Analysis of the width ratio and wear rate of maxillary anterior teeth in the Korean population. The journal of advanced prosthodontics 2017;9:93-8. https://doi.org/10.4047/jap.2017.9.2.93

22. JIN, Ming-Xu et al. Does the maxillary anterior ratio in Korean adults follow the Golden Proportion?. The journal of advanced prosthodontics 2016;8:125-30. https://doi.org/10.4047/jap.2016.8.2.125

23. Muhammad S, Rehman S, Muhammad IS. Tooth Morphology and Aesthetics While Smiling in Accordance to Golden Proportion. Pakistan journal of medical and health sciences 2016;10(1):281-4.

24. Ramirez LM, Ospina JD, Ballesteros LE. Mestizo Anterior Teeth's Proportions. International Journal of Morphology 2016;34(1). https://doi. org/10.4067/S0717-95022016000100032

25. Becerra Santos $\mathrm{G}$ et al. Algunos factores relacionados con la estética dental: una nueva aproximación. Revista Facultad de Odontología Universidad de Antioquia 2015;26(2):271-91.

26. Zhao Q, Li N, Cao J. Morphological features of maxillary anterior teeth in a sample of Chinese population. HOMO - Journal of Comparative Human Biology 2015;66:448-54. https://doi.org/10.1016/j.jchb.2015. 06.001

27. Sah SK et al. Maxillary anterior teeth dimensions and proportions in a central mainland chinese population. The Chinese journal of dental research: the official journal of the Scientific Section of the Chinese Stomatological Association (CSA) 2014;17(2):117-24.

28. Forster A, Velez R, Antal M, Nagy K. Width ratios in the anterior maxillary region in a Hungarian population: addition to the golden proportion debate. The Journal of prosthetic dentistry 2013;110:211-5. https://doi org/10.1016/S0022-3913(13)60359-5

29. Alam MK et al. Multiracial facial golden ratio and evaluation of facial appearance.PloS one 2015;10:e0142914.

30. Al-Marzok MI, Majeed KRA, Ibrahim IK. Evaluation of maxillary anterior teeth and their relation to the golden proportion in Malaysian population. BMC oral health 2013;13:9. https://doi.org/10.1186/14726831-13-9

31. Parnia F et al. Proportions of maxillary anterior teeth relative to each other and to golden standard in tabriz dental faculty students. Journal of dental research, dental clinics, dental prospects 2010;4(3):83.

32. Soares GP et al. Prevalência da proporção áurea em indivíduos adultosjovens. Revista Odonto Ciência 2006;21(4):346-50. 
33. Santos PCFdos et al. Estudo das proporções dentárias utilizando os métodos de Bolton e Levin. Full dent. sci 2016;7.26:104-13.

34. Da Cunha LF et al. Premium protocol for planning a periodontal-restorative approach: Conservative, predictable, and reproducible. Quintessence International 2017;48.7.

35. Da Cunha LF et al. Cleidocranial dysplasia case report: remodeling of teeth as aesthetic restorative treatment. Case reports in dentistry 2014

36. Pini NP et al. Analysis of the golden proportion and width/height ratios of maxillary anterior dentition in patients with lateral incisor agenesis. Journal of Esthetic and Restorative Dentistry 2012;24.6:402-14. https:// doi.org/10.1111/j.1708-8240.2012.00533.x

37. Bukhary SMN et al. The influence of varying maxillary lateral incisor dimensions on perceived smile aesthetics. British dental journal 2007; 203.12:687-93.

38. Akan S, Torgut AG, Oktay H. Effects of malocclusions on facial attractiveness and their correlations with the divine proportion. Journal of Orofacial Orthopedics/Fortschritte der Kieferorthopädie 2017;1-10

39. Anand, S, et al. Vertical and horizontal proportions of the face and their correlation to phi among Indians in Moradabad population: A survey. The Journal of the Indian Prosthodontic Society 2015;15.2:125.

40. Sandeep, N, et al. An analysis of maxillary anterior teeth dimensions for the existence of golden proportion: clinical study. Journal of international oral health: $\mathrm{JIOH} \mathrm{2015;7.9:18}$

41. Chander, NG., Kumar, VV., e Rangarajan, V. Golden proportion assessment between maxillary and mandibular teeth on Indian population. The journal of advanced prosthodontics 2012;4(2):72-5. https://doi.org/10.4047/ jap.2012.4.2.72

42. Saha, MK, et al. Perception of Acceptable Range of Smiles by Specialists, General Dentists and Lay Persons and Evaluation of Different Aesthetic Paradigms. Journal of clinical and diagnostic research: JCDR 2017;11.2:ZC25

43. Basting, RT., Trindade, RS e Flório, FM. Comparative study of smile analysis by subjective and computerized methods. Operative dentistry 2006;31(6):652-9. https://doi.org/10.2341/06-24

44. Ong, E., Brown, RA e Richmond, S. Peer assessment of dental attractiveness. American journal of orthodontics and dentofacia orthopedics 2006;130(2):163-9. https://doi.org/10.1016/j.ajodo. 2005.02.018

45. Koidou, VP., Chatzopoulos, GS, e Rosenstiel, SF. (2017). Quantification of facial and smile esthetics. The Journal of Prosthetic Dentistry.

46. Nikgoo, A, et al. Assessment of the golden ratio in pleasing smiles. World journal of orthodontics 10.3, 2009

47. Murthy, BS., e Ramani, N. Evaluation of natural smile: Golden proportion, RED or Golden percentage. Journal of conservative dentistry: JCD 2008:11(1):16.

48. Raj, V. Esthetic paradigms in the interdisciplinary management of maxillary anterior dentition - a review. Journal of Esthetic and Restorative Dentistry 2013;25(5):295-304. https://doi.org/10.1111/jerd.12028
49. Agrawal VS et al. Comparative photographic evaluation of various geometric and mathematical proportions of maxillary anterior teeth: A clinical study. Indian Journal of Dental Research 2016;27(1):32.

50. Marconato JC et al. Avaliação da proporção áurea no sorriso de pacientes submetidos ao tratamento ortodôntico. Journal of Health Sciences 2015;14(3).

51. Calçada, D, Correia, A e Araújo, F. Anthropometric analysis of anterior maxillary teeth with digital photography-a study in a Portuguese sample. The international journal of esthetic dentistry 2014;9(3):370-80

52. Frese $C$, Staehle HJ, Wolff D. The assessment of dentofacial esthetics in restorative dentistry: a review of the literature. The Journal of the American Dental Association 2012;143(5):461-6. https://doi.org/10.14219/jada. archive.2012.0205

53. Petričević $\mathrm{N}$ et al. Appropriate proportions as guidelines in selection of anterior denture teeth. Medicinski Glasnik 2008:5(2):103-8.

54. Scolozzi P, Momjian A, Courvoisier D. Dentofacial deformities treated according to a dentoskeletal analysis based on the divine proportion: are the resulting faces de facto" divinely" proportioned? Journal of Craniofacial Surgery 2011;22(1):147-50

55. Ward DH. A study of dentists' preferred maxillary anterior tooth width proportions: comparing the recurring esthetic dental proportion to other mathematical and naturally occurring proportions. Journal of Esthetic and Restorative Dentistry 2007;19(6):324-39. https://doi.org/10.1111/j.1708 8240.2007.00114.x

56. Lukez $A$ et al. The unique contribution of elements of smile aesthetics to psychosocial well-being. Journal of oral rehabilitation 2015;42(4):275-81. https://doi.org/10.1111/joor.12250

57. Bragatto FP et al. Golden Proportion Analysis of Dental-Skeletal Patterns of Class II and III Patients Pre and Post Orthodontic-orthognathic Treatment. The journal of contemporary dental practice 2016;17(9):728-33. https:// doi.org/10.5005/jp-journals-10024-1920

58. Mayumi PS et al. Incidência da Proporção Áurea Regressiva após Tratamento Ortodôntico. Revista Odontológica do Brasil Central 2012;21-57.

59. De Andrade Brum CV et al. Estudo da Proporção Áurea em pacientes jovens Classe II, divisão 1 tratados ortodonticamente. Odonto 2010:18: 70-80

60. Prokopakis EP et al. The golden ratio in facial symmetry. Rhinology 2013;51

61. Ali Fayyad M, Jamani KD, Agrabawi J. Geometric and mathematical proportions and their relations to maxillary anterior teeth. J Contemp Dent Pract 2006;7(5):62-70

62. Wolfart $\mathrm{S}$ et al. Subjective and objective perception of upper incisors Journal of oral rehabilitation 2006;33(7):489-95. https://doi.org/10.1111/ j.1365-2842.2005.01581

63. Madeira MC. Anatomia da face: bases anátomo-funcionais para a prática odontológica. Sarvier; 2013. 